\title{
Seguridad Ciudadana: Un Desafío Nacional
}

Ramón Romero Cantarero*

\section{RESUMEN}

El riesgo en la seguridad de la ciudadanía proviene no solamente de la delincuencia, sino también del abuso de autoridad que predomina en quienes controlan la fuerza pública y el poder.

Cuando la sociedad participa activamente en la preservación de las condiciones de seguridad de su comunidad, se reducen las posibilidades de riesgos delincuenciales o de excesos de los agentes estatales. Cuanto más desarrollada es una sociedad, mayores son sus niveles de seguridad y, consecuentemente, cuanto más atrasada, más insegura; pero debemos admitir que no existe una sociedad absolutamente segura, ni absolutamente insegura. En ciertas condiciones hay mayor seguridad que en otras y un nivel de vida digno entre los ciudadanos, es un factor determinante para que una sociedad goce de un alto índice de seguridad.

El problema de la inseguridad es tan complejo que no se resuelve llenando las cárceles de delincuentes, porque se ha demostrado que aunque la población carcelaria aumenta, también aumenta la criminalidad. La falta de seguridad en Honduras no es consecuencia únicamente de la delincuencia, sino también de los desastres naturales y de la inseguridad alimentaria. Los tres Poderes de Estado, incluyendo a la Policía, son los garantes de la seguridad de la ciudadanía. Cada uno debe asumir su diferente rol y complementarse.

\section{Palabras Clave: Inseguridad, Criminalidad, Delincuencia, Violencia, Corrupción.}

\section{ABSTRACT:}

Risks to citizen safety are not only induced by criminal acts and delinquent behavior, but also by a system dominated by national command authorities and other authority figures who abuse positions of power.

\footnotetext{
* Ramón Romero, ramonromero54@yahoo.es

Director de la Dirección de Vinculación Universidad-Sociedad, Miembro de la Junta de Dirección Universitaria (JDU). Universidad Nacional Autónoma de Honduras
} 
Private citizens active participation contributes to the protection of safety conditions within the community, reducing the likelihood of delinquent behavior and state agents abuses. More developed societies evince higher levels of safety, consequently, less developed societies are more insecure, yet it must be stated that there is no absolutely safe or unsafe society. Safety may improve under certain conditions; a decent standard of living is a decisive factor for accomplishing high safety levels.

Lack of safety is such a complex problem that is not solved by filling prisons. It has been proved that even though inmate population increases, crime rates also increase. Delinquency is just part of the problem; natural disasters and food insecurity also play their part in the lack of safety in Honduras. The three powers of the State, including the police, should assume separate roles and complement each other, guaranteeing citizens safety.

Keywords: insecurity, criminality, deliquescence, violence,corruption 


\section{LASEGURIDAD DE LOS CIUDADANOS EN LADEMOCRACIA}

\section{Grado de riesgo y grado de inseguridad}

Una sociedad es segura para sus ciudadanos cuando las personas y grupos que en ella interactúan pueden desarrollar sus actividades lícitas sin enfrentar riesgos provocados por otras personas, grupos o instituciones, que puedan afectar su vida, su integridad física o psíquica, su libertad, su patrimonio y el goce y ejercicio de sus derechos y garantías constitucionales.

Cuando en una sociedad es riesgoso para las personas o para su patrimonio el ejercer actividades lícitas, esta sociedad es insegura. El grado de riesgo para las personas o sus bienes es, entonces el elemento determinante de la condición de seguridad o inseguridad ciudadana existente.

El riesgo en materia de seguridad ciudadana es causado principalmente por la acción delincuencial y por los excesos autoritarios y arbitrarios cometidos por representantes del Estado que controlan la fuerza pública o el poder. Tanto la delincuencia como la arbitrariedad cometida por representantes del Estado, están a su vez altamente determinadas por factores de carácter social, económico, político y cultural. Así, los altos grados de polarización económico-social, el poder arbitrario de las instituciones armadas y policiales del Estado, la inestabilidad política, la exclusión social o la inequidad de género influyen de manera decisiva para que una sociedad sea menos segura para sus ciudadanos. En una sociedad sin graves polarizaciones, usos indebidos de la fuerza pública ni exclusión social, con aceptables niveles de ocupación laboral, acceso a los servicios de salud, educación y vivienda en suficiente medida como para permanecer saludable y productivo, con buen nivel de integración familiar y de cohesión y colaboración social, con prácticas ciudadanas de supervisión y control del poder público y con posibilidades de llevar su vida en ambientes de libertad y tolerancia, los riesgos ocasionados por la delincuencia y por la arbitrariedad del Estado son mucho menores que en sociedades donde tales condiciones no existan o estén viniéndose a menos. Además, en las sociedades más seguras las posibilidades de aumento de riesgos delincuenciales 0 de excesos de los agentes estatales son menores, porque la comunidad está en actitud y ánimo de participar en la preservación de sus niveles de vida y condiciones de seguridad.

No existe una sociedad absolutamente segura, ni absolutamente insegura. En ciertas condiciones hay mayor seguridad que en otras. Sí es evidente una 
correlación entre los niveles de desarrollo humano de una nación y sus niveles de seguridad. La tendencia es que son sociedades más seguras aquellas en que sus ciudadanos gozan de un nivel de vida digno, se mantiene respeto activo por sus derechos y garantías individuales y colectivas, y se sucede la más amplia participación democrática.

\section{Garantes de la seguridad ciudadana}

Otra característica de la seguridad ciudadana se refiere al actor o los actores sociales que la garantizan. La seguridad ciudadana está garantizada por la ciudadanía misma y por el Estado en sentido amplio, y no sólo por la parte del Estado que monopoliza la fuerza, esto es, la policía y las fuerzas armadas. En una sociedad democrática la fuerza armada no tiene funciones en relación con la seguridad de los ciudadanos, y la policía es la institución más directamente responsable de la seguridad de la ciudadanía. El Poder Legislativo y el Judicial, así como el sistema penal complementan su acción con el Ejecutivo para proveer a la ciudadanía del aporte estatal en la construcción de seguridad ciudadana.

La asociación complementaria entre ciudadanía y Estado para construir seguridad ciudadana es resultado de un avanzado proceso de democratización. Este proceso no está, en el caso de Honduras, tan avanzado como para que tal complementariedad se suceda sin obstáculos de muy distinto tipo. Desde la percepción autoritaria en que hemos estado inmersos, la seguridad ha sido un tema no sólo estatal, sino exclusivamente militar y policial. Además durante un largo período, el objetivo de seguridad ha sido principalmente el Estado y no la ciudadanía. Más aún, ha habido períodos en los cuales preservar al Estado de las amenazas externas, o aún internas, llegó a significar el proteger al Estado frente a la ciudadanía. La doctrina de la seguridad nacional ha sido la ideología más elaborada al respecto.La seguridad ciudadana es contraria a la doctrina de seguridad nacional tanto en sus objetivos como en sus métodos y estrategias. Asumirla y ejecutarla implica el reto de modificar actitudes tanto en el Estado como en la ciudadanía, para que ambos asuman roles diferentes pero complementarios en una tarea compartida, en la cual la ciudadanía no es el colaborador eventual, medio 0 instrumento de la policía, sino el socio o interlocutor del Estado, en un contexto de responsabilidades compartidas.

Esta idea de seguridad ciudadana no invalida otras dimensiones del concepto de seguridad, que incluyen factores de riesgo distintos a la delincuencia, como las sequías en materia de seguridad alimentaria, o el sistema de alerta temprana para crear seguridad ante desastres naturales. Se plantea más bien como una 
dimensión más, una entre otras, del concepto más amplio de seguridad integral, que Naciones Unidas está actualmente denominando "Seguridad Humana".

\section{LAPRECARIEDAD DE LASEGURIDAD CIUDADANA}

\section{Creciente inseguridad}

El aumento de la inseguridad no es privativo de Honduras o Centroamérica. Se ha estado sucediendo en toda América Latina durante la última década. Las ciudades latinoamericanas son hoy más inseguras que hace diez años (Kliksberg, 2001). Hay consenso entre los estudiosos del tema en afirmar que la proliferación de la delincuencia es la causa principal de la inseguridad de los ciudadanos existiendo una relación inversamente proporcional, en la cual a menor delincuencia, mayor seguridad ciudadana.

La criminalidad ha sido considerada por la Organización Panamericana de la Salud como un problema central de salud pública, pues entre otras cosas, se ha constituido en una de las principales causas de muerte de población joven.

Los gastos públicos y privados en seguridad son impresionantes y siempre crecientes. Según datos del BID (2001), el 10.3\% del producto interno bruto de Brasil y el $24 \%$ del mismo en Colombia se dedicaron a la seguridad, sin lograr reducir los índices de criminalidad y distrayendo fundamentales recursos de otras áreas del gasto público y productivo.

Un resultado de la inversión en seguridad ha sido el crecimiento en toda América Latina de la población retenida en cárceles y reclusorios. Sin embargo, pese a tanta inversión pública y privada, y pese también al fuerte crecimiento de la población carcelaria, las tasas de criminalidad están ascendiendo. La población en cárcel ha aumentado sin que se produjera la esperada disminución de la criminalidad, especialmente en las ciudades. Ello evidencia que el tema es de gran complejidad.

Múltiples encuestas de opinión muestran que la ciudadanía tiene una sensación de inseguridad, y que éste es uno de los problemas que más le preocupa. Tales percepciones se fundan en hechos como el ascenso reciente e ininterrumpido de las tasas de criminalidad. En América Latina durante el año 2002 se producian 30 homicidios anuales por cada 100,000 habitantes; en Honduras durante el año 2000 la tasa fue de 60 homicidios por 100,000 habitantes, mientras en 1996, en El Salvador esa tasa fue de 139 (Moser y Winton, 2002, P. Vii). 
En el año 2005 en los departamentos hondureños de Francisco Morazán, Cortés, Atlántida y Copán hubo más de 37 homicidios por cada 100,000 habitantes. En el año 2006 en los mismos departamentos la tasa subió a más de 60 homicidios por 100,000 habitantes. En 2007 por cada 100,000 habitantes hubo 63.9 homicidios en Francisco Morazán, 77.2 en Cortés, 76.4 enAtlántida y 73.8 en Copán. Estos cuatro departamentos hondureños se han mantenido como los más violentos y con la mayor tasa de homicidios durante al menos los últimos tres años (Observatorio de la Violencia. UNAH. 2008). A principios de la presente década, un estudio británico (Moser y Winton, 2002) señaló tres causas estructurales de la violencia en Honduras, Guatemala, El Salvador y Nicaragua:

1. El legado de violencia política y el conflicto en la región.

2. La proliferación de armas en la América Central posconflicto, con tráfico transregional.

3. La pobreza severa, la desigualdad y la exclusión en la distribución de los recursos económicos, políticos y sociales.

A esas causas deben agregarse, seis años después, otras siempre de carácter estructural, como las siguientes:

1. La expansión ininterrumpida del crimen organizado transnacional, especialmente el narcotráfico, que ya ha absorbido y puesto a su servicio a otros sujetos delincuenciales de menor envergadura, como las pandillas, y cuya capacidad de corrupción ha penetrado la institucionalidad del Estado, la política y algunos sectores empresariales.

2. La debilidad del Estado para enfrentar la delincuencia de manera efectiva y sostenida.

3. El temor de unos ciudadanos y la indiferencia de otros, ante la perspectiva de involucrarse en el tema de la seguridad, asumiendo que esta es una función exclusivamente estatal y principalmente policial.

\section{Efectos sociales de la inseguridad y la violencia}

La inseguridad y la violencia generan graves efectos para las personas, pero también para las sociedades. Entre estos últimos, algunos de los más relevantes son:

1. Aumenta la pobreza, impactando en la reducción de posibilidades de acceso a los medios de subsistencia de los ciudadanos.

2. Reduce los espacios democráticos, llevando a la desnaturalización del Estado de Derechoy de la representación, inhibiendo la participación y generando 
desconfianza e irrespeto en las instituciones, así como fortaleciendo las respuestas autoritarias y violentas.

3. Cotidianiza la violencia, el crimen y todo tipo de delincuencia, haciéndolo sentir una especie de condición natural de la existencia.

4. Crea la convicción de vivir bajo el imperio de la ley de la selva, o el estado de naturaleza, en el que no hay normas morales ni jurídicas, sino el imperio de los más fuertes.

5. Genera un ambiente de desmoralización, pesimismo y fatalismo en amplios segmentos de la población, reduciendo la voluntad de participar en la solución de los problemas y aceptando con resignación vivir en inseguridad.

6. Lleva a otros segmentos de población a actuar violentamente por su propia cuenta, para reprimir delincuentes, al margen de la institucionalidad del Estado, o a incorporarse activamente en los grupos delincuenciales.

7. Erosiona los nexos de cooperación y los mecanismos de cohesión social necesarios para el funcionamiento de la sociedad.

8. Reduce la condición saludable de las personas y aumenta el gasto público y privado en salud.

9. Afecta negativamente el funcionamiento de instituciones sociales.

10. Reduce la producción y la productividad de las personas y las empresas.

11. Reduce las posibilidades de captar inversión extranjera.

\section{Tres tipos de delincuencia}

Diversos estudios sobre la delincuencia coinciden en reconocerla como un fenómeno complejo, ocasionado por causas múltiples, procedente de distintas fuentes y ejecutada por distintos autores. Hay consenso entre estudiosos de la seguridad en América Latina en reconocer al menos tres tipos de delincuencia claramente diferenciados, pero al mismo tiempo vinculados entre sí: El crimen organizado, los delitos de corrupción y la delincuencia común.

\section{Crimen organizado}

El crimen organizado es el que se practica por bandas o grupos transnacionales involucrando elevadas sumas de dinero, con nivel sofisticado de planeación y organización, con capacidad tecnológica con frecuencia superior a la del Estado, vinculados nacional e internacionalmente con otros grupos delictivos, con funcionarios y empleados públicos, incluyendo nexos con miembros de la propia policía y organismos de seguridad. Tanto en niveles de dirección como de operatividad, en este tipo de crimen se involucra personal entrenado, con capacidad técnica y operativa, procedente de las Fuerzas Armadas, antiguos cuerpos de 
seguridad del Estado, grupos paramilitares, batallones clandestinos, ex miembros de grupos armados insurreccionales y aún por miembros activos en los organismos de seguridad y en las Fuerzas Armadas. Este tipo de crimen no se origina como estrategia de sobrevivencia en condiciones de pobreza, sino al contrario, es dirigido por delincuentes ubicados en las clases medias o en sectores económicamente poderosos y cercanos al poder, cuyo objetivo es la ganancia económica, el enriquecimiento extremo y la mantención del poder económico. Todo ello le permite operar con los más altos niveles de impunidad. En su práctica el crimen organizado usa indiscriminadamente de la violencia y suele tener sofisticados arsenales, así como gran capacidad logística y operativa para ejercer la violencia. Es el crimen de las mafias, carteles y bandas. Opera en campos como el narcotráfico, secuestro de personas, robo de vehículos y contrabando. Además es el que opera el llamado "lavado de activos" o inversión lícita de dinero proveniente de actividades delictivas como el narcotráfico. En el año 2007, 690 de los homicidios consumados en Honduras, que equivale al $21.2 \%$ del total nacional de homicidios de dicho año, fueron cometidos en relación con el crimen organizado, en actividades de sicariato, bandas y narcotráfico (Observatorio de la Violencia, UNAH, 2008).

\section{Los delitos de corrupción}

Los delitos de corrupción son ejercidos por funcionarios y empleados públicos en complicidad con ciudadanos de los más diferentes estratos sociales. La corrupción está configurada por una amplia diversidad de delitos, entre ellos abuso de autoridad y violación de los deberes de los funcionarios, cohecho, malversación de caudales públicos, negociaciones incompatibles con el ejercicio de funciones públicas, fraudes y exacciones ilegales, prevaricación, denegación y retardo de justicia, falso testimonio, acusación o denuncia falsa, encubrimiento, evasión, tráfico de influencias, enriquecimiento ilícito de funcionarios públicos, usurpación de funciones públicas, abuso de funciones públicas, desobediencia, soborno, infidelidad a los deberes profesionales, fraude procesal, violación de sellos y documentos.

Los delitos de corrupción mayor son los que causan más perjuicio al Estado y consecuentemente a la ciudadanía. Estos incluyen las más grandes cantidades de dinero e involucran a importantes funcionarios y empleados públicos, así como a ciudadanos de los más altos estratos económicos y políticos. En las prácticas de corrupción tradicionalmente han participado políticos, funcionarios y empleados del Poder Ejecutivo central y descentralizado, diputados, jueces, policías, miembros de corporaciones municipales, periodistas, empresarios, profesionales en distintas ramas, y cualquier ciudadano que requiera favores o beneficios ilegales a cambio 
de una paga. Su cercanía a los más elevados círculos de poder en el Estado es determinante sobre su nivel de impunidad: a mayor cercanía, más alto grado de impunidad.

Algunas características relevantes de los delitos de corrupción son las siguientes:

1. No son causados por la extrema pobreza o por condiciones de exclusión social.

2. Sus ejecutores se ubican social y económicamente en las clases altas y medias.

3. No necesitan del uso de la violencia.

4. Tienden a pasar bastante desapercibidos por la ciudadanía, pues no se hacen evidentes de inmediato y sólo se conocen al ser investigados.

5. Requieren de la participación de funcionarios o empleados públicos.

6. Los de mayor magnitud suelen tener apoyo político.

7. Se suceden en cadena: la sustracción de caudales públicos o el fraude suelen llevar al cohecho o al soborno de funcionarios o empleados, y este a su vez suele extenderse a órganos fiscalizadores, policías, jueces y empleados judiciales.

8. Son difíciles de probar, debido a que quienes los practican eliminan evidencias 0 pruebas, para garantizar su impunidad.

9. Los delincuentes de otro tipo, especialmente del crimen organizado usan de la corrupción para encubrir sus otros delitos y reducir o eliminar las consecuencias legales de sus otros delitos, logrando impunidad. En Honduras la mayor parte de estos delitos quedan no sólo en la impunidad, sino en el silencio y el desconocimiento, dificultando esto la cuantificación de sus montos. Distintos sectores especulan que anualmente la corrupción en Honduras asciende a sumas variables entre dos mil millones y cinco mil millones de lempiras.

\section{La delincuencia común}

Es la forma más generalizada de delincuencia y ha sido la de más larga presencia, durante muchos años, aunque con menor intensidad que actualmente. Ella incluye los delitos comunes ejecutados principalmente por personas en condición de pobreza o exclusión social, con el móvil de la ganancia ilegítima e ilegal; también la violencia social es parte de la delincuencia común. La llamada violencia social hace referencia a la comisión de actos violentos motivados por un deseo de ganancia social, para obtener o mantener el poder la dentro de la familia, la comunidad 0 grupo.

La criminalidad común es altamente visible, con la sola excepción de la violencia doméstica. Esta última tiende más bien a ser invisibilizada y a pasar desapercibida 0 tenida como parte de la vida cotidiana. 
Algunas formas de la delincuencia común son el hurto y el robo callejero y en autobuses, lesiones contra las personas, homicidio y asesinato, violación y abusos sexuales contra niños y adultos, rapto y estupro, distribución local de drogas, destrucción de propiedad, intimidación y aterrorización de la población, extorsión, chantaje, cobro de "impuestos" por penetrar a territorios controlados por la delincuencia común y violencia intrafamiliar contra las mujeres y niños.

Las principales características de la delincuencia común son:

1. Es ejecutada en su mayoría por personas o grupos en condiciones de pobreza 0 exclusión social. Estos ejecutores tienden a caracterizarse, además, por ser jóvenes, laboralmente en condición de desempleo, con bajo nivel de escolaridad y provenientes de hogares desintegrados o sin hogar.

2. Las víctimas tienden a ser otros pobres, personas de su mismo status socioeconómico o de las capas medias. Uso indiscriminado de la violencia principalmente con armas corto punzantes y armas de fuego de diversos calibres, muchas de ellas de fabricación artesanal.

3. Los ejecutores tradicionalmente han operado individualmente, pero en los últimos años ha cobrado alto protagonismo un nuevo sujeto de tal delincuencia: las pandillas o maras.

4. Los vínculos con el crimen organizado son crecientes. En tales vínculos los delincuentes comunes se constituyen en brazos ejecutores de acciones delictivas ordenadas por el crimen organizado.

5. Los delincuentes comunes con frecuencia mantienen vínculos de complicidad con miembros de los cuerpos policiales, quienes los protegen o les permiten operar a cambio de compartir ganancias.

6. Las acciones de delincuencia común, junto con las del crimen organizado, alimentan las páginas rojas de los periódicos y otros medios de comunicación, que generalmente los difunden con sensacionalismo morboso, que induce en los ciudadanos comunes sentimientos de inseguridad, inhibición, desconfianza, angustia, clamor por el ejercicio estatal de mano dura e incremento de medidas represivas, cambios en las conductas normales, e instrumentalización de tales temores e inseguridades por grupos o sectores políticos, militares y policiales que pretenden legitimación o recuperación de influencias políticas o privilegios perdidos.

7. Al ser más publicitada, la delincuencia común se convierte en la forma de delincuencia más presente en la mente de las personas. Sin embargo la noticia periodística suele presentarse descontextualizada, llevando con ello a la población a tener una idea deformada sobre tal tipo de delincuencia. Ello vuelve 
imperativa la necesidad de conocer más en profundidad este tipo de delincuencia y sus impactos socio-económicos.

8. El estudio de la delincuencia común como fenómeno estructural, explicado dentro del contexto social, económico, político y cultural del que es parte, permite evidenciar que los índices de criminalidad causada por la delincuencia común han subido paralelamente al deterioro de las condiciones de vida de la población. El crecimiento de la pobreza, la elevación de las tasas de desocupación abierta, la degradación de la calidad de los trabajos disponibles, especialmente en el sector informal, la limitada cobertura y acceso de amplios sectores de población a los servicios adecuados de salud pública, educación y vivienda, la condición de alto riesgo alimentario en que se encuentran especialmente los niños, forman elementos centrales del marco de deterioro social en el que vive más del $70 \%$ de la población de Honduras. A ello se suma el aumento de las polarizaciones sociales, por las cuales América Latina es hoy la región más desigual de todo el planeta, en la cual el $10 \%$ más rico de la población tiene 84 veces el ingreso del $10 \%$ más pobre. Según diversos analistas, en tales condiciones la desigualdad es el obstáculo principal al crecimiento económico sostenido. La pobreza se ha aumentado además con la incorporación de los llamados "nuevos pobres", procedentes de las clases medias como resultado de aplicación de muchas medidas de ajuste estructural de la economía.

Éste es el clima en el que se sucede la delincuencia común. Según Bernardo Kliksberg (2001), hay tres correlaciones, estadísticamente evidenciables, entre el proceso de deterioro social y el aumento de la criminalidad, que deben ser destacadas:

1. La correlación entre el ascenso de la delincuencia y las tasas de desocupación juvenil. Las ya elevadas tasas de desocupación general son aún más altas entre los jóvenes llegando a triplicarlas. Un alto porcentaje de la población joven tiene vedadas las posibilidades de insertarse en la economía, o sólo puede lograr ingresos que lo ubican por debajo del umbral de la pobreza. A ello se suma la caída del poder adquisitivo de los salarios, principalmente de los mínimos salariales. Según análisis del Nobel de Economía Robert Solow, los que por largos períodos permanecen desocupados y sin insertarse en la economía, tienden a abandonar del todo la búsqueda de trabajo para evitar nuevos rechazos que pueden afectarlos más, aún y cuando su situación es ya altamente vulnerable; su autoestima personal está muy dañada, su personalidad se resiente y tienden a retraerse socialmente. Esta población joven es a la vez el segmento poblacional más vinculado con la delincuencia común, tanto en condición de ejecutores como de víctimas. 
2. Una segunda área de correlaciones es la que vincula deterioro familiar con delincuencia. Al menos dos terceras partes de los jóvenes internados por delitos provienen de familias desintegradas u hogares con un solo cónyuge al frente. Esta correlación evidencia la importancia de la familia en la prevención del delito. Si una familia funciona bien "impartirá valores y ejemplos de conducta en las edades tempranas, que serán después fundamentales cuando los jóvenes deban elegir en sus vidas frente a encrucijadas difíciles. Sí entra en proceso de desarticulación deja de cumplir dicha función. Esta institución clave en la acción antidelictual está sufriendo severos deterioros bajo el impacto de la agravación de la pobreza. Numerosas familias pobres y de clase media sufren privaciones económicas graves y tensiones extremas ante períodos de desocupación prolongada que terminan por desarticular la familia." (Kliksberg, 2001). A ello se agrega, como parte de la correlación, el crecimiento de los índices de violencia doméstica, una de cuyas razones es el alto stress socio económico sufrido por la gran mayoría de familias pobres. A su vez, la violencia en el hogar insensibiliza ante el uso de la violencia en estructuras más amplias de la vida social, e inclusive puede condicionar y preparar para la misma.

3. Una tercera correlación se observa entre niveles de educación y delincuencia común. La tendencia es que si aumentan los grados de educación de una población, descienden los índices delictivos comunes. Los fenómenos que más afectan la reducción de los niveles educativos son la deserción escolar y la repetición. Tanto la deserción como la repetición están incididas por la pobreza. Ella conduce al trabajo infantil, como a la desnutrición y a otras carencias.

Estas tres correlaciones evidencian que la alta desocupación juvenil, las familias desarticuladas y los bajos niveles de educación de la población joven son factores que operan silenciosamente como determinantes en alto grado de la delincuencia común que actualmente padecen nuestras sociedades.

\section{TRES DESAFÍOS INSTITUCIONALES EN LA CONSTRUCCIÓN DE SEGURIDAD CIUDADANA}

La construcción de seguridad ciudadana debe enmarcarse dentro de un proyecto más general de democratización y de desarrollo. Es un componente del proyecto de nación, que involucra dimensiones sociales, económicas, políticas y culturales, y que se intersecta y complementa con otros grandes propósitos como la eliminación de la pobreza y la obtención de una vida de mayor calidad para todos los ciudadanos.

Para construir seguridad ciudadana se requiere tanto de la institucionalidad 
democrática, como del disfrute ciudadano de las garantías y derechos fundamentales. Entre los aspectos institucionales básicos para la construcción de seguridad ciudadana destacan:

1. La plena vigencia del Estado de Derecho, esto es, de un Estado en el cual la supremacía del imperio de la ley, la seguridad jurídica, la inexistencia de la impunidad y el efectivo respeto y ejercicio de las garantías, derechos y libertades ciudadanas sean los determinantes exclusivos de los alcances y límites de la acción del Estado. El Estado pleno de Derecho es, en Honduras, un Estado por construir. Tenemos un Estado débil o fracasado, caracterizado por su incompetencia para hacer cumplir las leyes, ejecutar los programas de gobierno, controlar la corrupción y cumplir el pacto social entre el Estado y la ciudadanía, contenido en la Constitución de la República. Esta es una de las grandes causas generadoras de inseguridad ciudadana. El Estado fuerte por construir, no es lo mismo que Estado autoritario. El Estado fuerte por excelencia es el Estado de Derecho, en el cual un elemento esencial de la estatalidad es la aplicación de las leyes, incluyendo la capacidad de última instancia de "enviar a alguien con uniforme y pistola para que imponga el cumplimiento de las leyes del Estado." (Fukuyama, Francis, 2004, p. 22).

2. La disposición del Estado para reconocer como su interlocutor y socio a la ciudadanía, y su decisión de no intervenir en los procesos de conformación de su voluntad, respetando plenamente la autonomía de este sujeto social. El Estado debe asumir que la seguridad ciudadana se construye mediante su asociación con la ciudadanía, cumpliendo cada uno, roles diferentes pero complementarios. En materia de seguridad ciudadana la participación de la ciudadanía se sucede al menos en los siguientes sectores:

a. Vigilancia vecinal, comunal y local con carácter eminentemente preventivo.

b. Denuncia de hechos delictivos por los canales establecidos, ante las autoridades competentes.

c. Información confiable a las autoridades competentes conducente al esclarecimiento de hechos, captura de delincuentes y demás acciones de prevención, control y sanción.

d. Proposición de iniciativas, planes y proyectos, ante las instancias públicas que corresponda, tendentes a elevar el nivel de seguridad ciudadana en cualquiera de sus áreas.

e. Vigilancia del comportamiento institucional de los cuerpos policiales, de sus agentes y demás instituciones que trabajan en acciones de prevención, control y sanción. 
f. Integración de los organismos e instancias públicas en que se habilite la participación de la ciudadanía.

g. Ejercer controles sobre la actuación de los organismos públicos de seguridad.

h. Demandar transparencia en las gestiones de todo tipo efectuadas por los organismos de seguridad.

i. Presentación de quejas sobre comportamientos indebidos de las autoridades policiales en el cumplimiento de sus funciones.

j. Evaluación de los organismos públicos que trabajan en el área de seguridad ciudadana.

k. Recibir las cuentas que a la ciudadanía le rindan sobre su gestión las instituciones públicas de seguridad y pronunciarse sobre tales rendiciones de cuentas.

I. Prevenir los riesgos a la seguridad ciudadana mediante la ejecución de programas, planes y proyectos de atención a personas, en áreas sociales, económicas, educativas, de salud, culturales, éticas, de rehabilitación, de capacitación, de recreación, de deportes, de inserción en el mercado laboral, etc. dirigidos a los jóvenes, a los pobres y excluidos, a grupos más vulnerables, a delincuentes, a las maras o pandillas juveniles, a víctimas de la delincuencia, a integrantes de los organismos de seguridad, a organizaciones comunales y a la ciudadanía en general.

m. Promover una perspectiva de valoración del ser humano como un fin en sí mismo y jamás un medio para nada ni para nadie, que sirva de fundamento a una actitud humanista, en la que se privilegie el amor a la vida, la justicia la convivencia pacífica, el sentido de servicio, el voluntariado y el compromiso con los más necesitados.

3. El énfasis en la prevención juvenil. En materia de prevención deben aumentarse las oportunidades ocupacionales para los jóvenes, invirtiendo fuertemente en programas efectivos para la creación de espacios a jóvenes que están fuera del mercado de trabajo y del sistema educativo, expandir sus posibilidades de acceso a actividades culturales y deportivas, desarrollar políticas sistemáticas de protección a la familia y fortalecer la educación pública. Según cálculos del economista laureado con el premio Nobel Joseph Stiglitz, arrestar a un delincuente joven, juzgarlo y encarcelarlo es mucho más costoso que invertir en que tuviera la posibilidad de una beca para estudiar, con la diferencia notable de que lo segundo reduce la tasa de criminalidad, y lo primero no. Este razonamiento, pensado para los Estados Unidos, parece tener validez también en Honduras al calcular los costos nuestros en uno y otro caso. La sociedad civil y el Estado deben coordinar sus esfuerzos para concertar acciones comunitarias 
de creación de oportunidades de trabajo y desarrollo para los jóvenes desfavorecidos. Este es el componente central de una estrategia de prevención concebida a mediano plazo. Hacer lo contrario, concentrarnos en un enfoque eminentemente punitivo y dejar en suspenso derechos básicos garantizados por la Constitución y las leyes, reduce considerablemente la condición democrática y la calidad de vida para todos, y nos lleva a correr el grave riesgo de criminalizar la pobreza haciendo crecientemente de los pobres "sospechosos en potencia" de los cuales hay que protegerse, o peor aún, a quienes hay que mantener encerrados tras barreras protectoras.

En el marco de estos grandes desafíos se inscriben las iniciativas más puntuales, de corto, medio y largo plazo, que incluyen a la policía, operadores de justicia, sistema penitenciario, los distintos órganos del Estado, la ciudadanía, los empresarios, los gremios y la sociedad civil. Lograr un pleno Estado de Derecho, un elevado grado de asociación entre Estado y ciudadanía, y enfatizar en la prevención juvenil, son los componentes básicos que deben orientar la política pública y la estrategia de seguridad ciudadana.

\section{BIBLIOGRAFÍA}

Alkire, Sabina. 2002. Conceptual framework for human security. Washington: (Material mimeografiado).

Castellanos, Julieta. 2000. Honduras: armamentismo y violencia. Tegucigalpa: Fundación Arias para la Paz y el Progreso Humano, CIPRODEH, Foro Ciudadano.

Castellanos, Julieta. 2008. Seguridad, los retos del Estado de Honduras. En: Segundo Congreso de Investigación Científica. Tegucigalpa. Observatorio de la Violencia UNAH. [soporte electrónico]

Castellanos, Julieta. 1997. La Inseguridad ciudadana. Tegucigalpa: CEDOH.

Dower, Nigel. 1995. Peace and security: some conceptual notes. In: Essays on

Peace. Reino Unido: Central Queensland University Press.

Foro Nacional de Convergencia. 2000. Propuesta plan integral de seguridad de las personas y sus bienes. Tegucigalpa: (Material mimeografiado).

Fukuyama, Francis. 2004. La Construcción del Estado. Barcelona: Ediciones B. Honduras. 2002. Ley de policía y de convivencia ciudadana. Tegucigalpa. (Material mimeografiado)

Honduras. 1995. Tratado marco de seguridad democrática en Centroamérica. San Pedro Sula. (Material mimeografiado).

Honduras. Ministerio Público. 2002. Informe anual de labores 2001. junto al pueblo: por una justicia transparente, imparcial y democrática. 
Tegucigalpa.

Kliksberg, Bernardo. 2001. El Crecimiento de la criminalidad en América Latina:

un tema urgente. Washington: Banco Interamericano de Desarrollo: www.iadb.org/etica

Moser, Caroline y Ailsa Winton. 2002. Violencia en la región de América Central: hacia un marco de referencia integrado para la reducción de la violencia. Londres: Overseas Development Institute. (Material mimeografiado).

Rico, José M. y Luís Salas. Inseguridad ciudadana y policía. 1988. Madrid: Tecnos.

Romero, Ramón y Leticia Salomón. 2000. La reforma judicial: un reto para la democracia. Tegucigalpa: CEDOH.

Salomón, Leticia y Julieta Castellanos. 2000. La Reforma policial en Honduras. WOLA.

Salomón, Leticia. 1993. La Violencia en Honduras. Tegucigalpa: CEDOH.

Serbin, Andrés, Leticia Salomón y Carlos Sojo. 2001. Gobernabilidad democrática y seguridad ciudadana en Centroamérica. Managua: CRIES. 